\title{
Fisioterapia intradialítica na reabilitação do doente renal crônico
}

\author{
Exercise training during hemodialysis in the rehabilitation of \\ chronic kidney disease patients
}

\begin{abstract}
Autores
Raquel Jeanty de Seixas ${ }^{1}$

Cristiane Mecca

Giacomazzi²

Ana Elizabeth Prado

Lima Figueiredo ${ }^{3}$

${ }^{1}$ Reabilitação Cardiopulmonar PREMUS, PUC-RS

${ }^{2}$ Reabilitação Cardiopulmonar PREMUS, PUC-RS

${ }^{3}$ Unidade de Diálise e Transplante, Hospital São Lucas - PUC-RS/ PREMUS, PUC-RS
\end{abstract}

Data de submissão: 22/06/2009 Data de aprovação: 13/08/2009

Correspondência para: Cristiane Mecca Giacomazzi Av. Protásio Alves, 1.181/05 Porto Alegre - RS

CEP: 90410-001

Tel: (51) 9971-3062

Declaramos a inexistência de conflitos de interesse.

\section{Resumo}

$\mathrm{O}$ declínio da atividade física no doente renal crônico (DRC) é conhecido pela perda de força muscular ou pela redução progressiva no condicionamento e na funcionalidade. ${ }^{1}$ Por conta dessas manifestações, o tratamento do doente renal crônico, além de aumentar a sobrevida, também deve incluir reabilitação física. ${ }^{2}$ Cada vez mais estudos revelam que a participação da fisioterapia intradialítica é parte significativa dessa reabilitação. $\mathrm{O}$ estudo de Corrêa et al., "Efeito do treinamento muscular periférico na capacidade funcional e qualidade de vida nos pacientes em hemodiálise", ${ }^{3}$ vem, mais uma vez, confirmar que o DRC se beneficia com essa intervenção em sua rotina.

Palavras-chave: exercício físico, fisioterapia, hemodiálise.

[J Bras Nefrol 2009;31(3):235-236] CElsevier Editora Ltda.

\section{Prezado Editor}

O declínio da atividade física no doente renal crônico (DRC) é conhecido pela perda de força muscular ou pela redução progressiva no condicionamento e na funcionalidade. ${ }^{1}$ Por conta dessas manifestações, o tratamento da Doença Renal Crônica (DRC), além de aumentar a sobrevida, também deve incluir reabilitação física. ${ }^{2}$ Cada vez mais estudos revelam que a fisioterapia intradialítica é parte significativa dessa reabilitação. O estudo de Corrêa et al., "Efeito do treinamento muscular periférico na capacidade funcional e qualidade de vida nos pacientes em hemodiálise" (J Bras Nefrol 2009; 31(1):18-24), vem, mais uma vez, confirmar que o DRC se beneficia com essa intervenção em sua rotina.

\section{Abstract}

The decline in physical activity of patients with chronic kidney disease (CKD) is well known, due to either loss of muscle strength or progressive reduction in conditioning and function. ${ }^{1}$ Therefore, treatment of CKD besides increasing survival, should also include physical rehabilitation. ${ }^{2}$ More and more studies have shown that exercise training during hemodialysis plays a significant role in such rehabilitation. Corrêa et al., in their study "Effect of peripheral muscle training on functional capacity and quality of life in patients undergoing hemodialysis", ${ }^{3}$ have confirmed the benefits of that intervention in the routine of CKD patients.

Keywords: exercise training, physical therapy, hemodialysis.

Diferentes tipos de treinos têm sido realizados com pacientes em hemodiálise: aeróbico, de resistência e a combinação de ambos, não havendo ainda consenso sobre o melhor tipo. ${ }^{4}$ Porém, algumas doenças musculoesqueléticas decorrentes de "insuficiência" renal crônica ${ }^{5}$ demandam intervenção específica, e esse é um dos fatores que não permitem a participação de todos os pacientes em hemodiálise nos protocolos mais utilizados. Portanto, alguns estudos envolvem grupos pequenos de pacientes, como é o caso do estudo de Corrêa et al., ${ }^{3}$ já citado.

$\mathrm{Na}$ unidade de hemodiálise do Hospital São Lucas da PUC-RS, dos 36 indivíduos avaliados pela fisioterapia para o programa de exercício intradialítico, 11 necessitavam de adaptação. Desses, seis 
pacientes apresentavam problemas ortopédicos que impossibilitaram a participação no programa: necrose da cabeça do fêmur, sequela de acidente vascular cerebral, coxartrose, gonartrose e prótese de quadril com limitação funcional. Todos apresentavam algum tipo de limitação funcional e queixas físicas variadas.

Ao final, nove pacientes conseguiram participar do protocolo de exercícios (incluindo um deficiente visual), com a média de idade de 67,0 $\pm 16,2$ anos, sendo $66,6 \%$ do sexo feminino. A participação foi, em média, de 80,09\%. Assim como no estudo de Corrêa et al., utilizamos o teste de caminhada de seis minutos (TC6) para avaliação da capacidade funcional desses indivíduos. Após o programa de reabilitação, a distância percorrida aumentou significativamente $(\mathrm{p}=0,003)$, de uma média de 403,50 \pm 9,63 para 425 \pm 90,25 metros, respectivamente.

Portanto, o efeito do exercício físico intradialítico na funcionalidade dos participantes desse programa de fisioterapia se mostrou positivo, como evidenciado pela melhora no resultado do teste funcional. O exercício intradialítico se mostrou seguro. É necessário padronizar os testes para a realização de estudos, a fim de se analisar melhor o impacto dessa intervenção em tal população.
A diversidade de alterações musculoesqueléticas, bem como a melhora da capacidade funcional, reforçam a necessidade da presença do fisioterapeuta na reabilitação do DRC em hemodiálise. Esperamos que o crescente número de publicações incentive a pesquisa para beneficiar essa população.

\section{REFERÊNCIAS}

1. Zawada ET. Início da diálise. In: Daugirdas JT, Blake PG, Ing, TS. Manual de diálise. 3 ed. São Paulo, 2003, pp. 3-11.

2. Storer TW, Casaburi R, Sawelson S, Kopple JD. Endurance exercise training during haemodialysis improves strength, power, fadigability and physical performance in maintenance haemodialysis patients. Nephrol Dial Transplant 2003; 20:1429-37.

3. Corrêa LB, Oliveira RN, Cantareli F, Cunha LS. Efeito do treinamento muscular periférico na capacidade e qualidade de vida nos pacientes em hemodiálise. J Bras Nefrol 2009; 31:18-24.

4. Johansen, K. Exercise and dialysis. Hemodial Int 2008; 12:290-300

5. Vieira WP, Gomes KWP, Frota NB et al. Manifestações musculoesqueléticas em pacientes submetidos à hemodiálise. Rev Bras Reumatol 2005; 45:357-64. 